\title{
New Insight on Low-K Lettuce: From Photosynthesis to Primary and Secondary Metabolites
}

\author{
Hong-jia Xu, Masafumi Johkan, Toru Maruo, Natsuko Kagawa, \\ and Satoru Tsukagoshi \\ Graduate School of Horticulture, Chiba University, Chiba 271-8510, Japan; \\ and Center for Environment, Health and Field Sciences, Chiba University, \\ Chiba 277-0882, Japan
}

Additional index words. chlorophyll fluorescence, electric conductivity control, flavonoids, phenols, quantitative management

\begin{abstract}
With the increase in dialysis patients worldwide, the demand for low-K vegetables is growing. Thus, a type of lettuce with a low-K content has been marketed in Japan. To learn more about low-K vegetables, information is needed on the physiological differences between these vegetables and those with typical levels of potassium $(K)$. In this study, lettuces (Lactuca sativa $\mathbf{L}$.) were cultivated using two low-K management methods in an environment-controlled system. One method was based on electrical conductivity (EC) management, and the $\mathrm{K}$ was replaced by sodium $(\mathrm{Na})$ at the end of cultivation. The other method was based on quantitative nutrient management, and the nutrients required for low-K lettuce were quantitatively supplied, but no extra Na was added. Meanwhile, lettuce with normal $K$ concentration was cultivated with EC management as the control. Plant growth indices, leaf photosynthesis traits, chlorophyll fluorescence characteristics, concentrations of secondary metabolites (SMs), and antioxidant activity were examined to investigate the physiological effects of low-K and highNa concentrations during low-K lettuce cultivation. Both low-K treatments significantly restrained the growth of lettuce and increased the concentration of soluble sugar. However, photosynthesis and fluorescence characteristics remained unchanged. This indicates that the biomass reduction of low-K lettuce was due to the wasteful accumulation of carbohydrates rather than the decline in photosynthesis. Concentrations of SMs were increased in the low-K lettuce. In addition, higher concentrations of $\mathrm{Na}$ influenced the concentration of SMs, indicating that SMs were more sensitive to environmental stress.
\end{abstract}

In 2011 , there were $\approx 2.16$ million dialysis patients worldwide (Ogawa et al., 2012), and this number has increased. Dialysis patients have dysfunctional $\mathrm{K}$ excretion, which makes them vulnerable to hyperkalemia (Spital and Stems, 1988). Raw vegetables, which are often rich in $\mathrm{K}$, cannot be consumed by dialysis patients (Ogawa et al., 2012). Thus, there is a demand for the production of healthy, fresh edible low-K vegetables.

Recently, a type of lettuce with low-K content was marketed with a $\mathrm{K}$ concentration below $100 \mathrm{mg} \cdot 100 \mathrm{~g}^{-1}$ fresh weight (FW) (Tsukagoshi et al., 2016). The cultivation method used was the replacement of all the $\mathrm{K}$ in the growing solution with $\mathrm{Na}$ in the later stage of growth (Ogawa et al., 2012). In this method, the later nutrient solution contained a high concentration of $\mathrm{Na}$, of nearly 4

Received for publication 8 May 2020. Accepted for publication 21 July 2020.

Published online 4 March 2021.

M.J. is the corresponding author. E-mail: johkan@ faculty.chiba-u.jp.

This is an open access article distributed under the CC BY-NC-ND license (https://creativecommons. org/licenses/by-nc-nd/4.0/). element in plants, but it is involved in nonspecific functions, such as stimulation of plant growth and osmotic regulation (Wakeel et al., 2011). It is expected that the limited supply of $\mathrm{K}$ and $\mathrm{Na}$ accumulation in low-K lettuce could affect plant growth, but the underlying physiological changes caused by this remain unknown.

Photosynthesis and chlorophyll fluorescence are essential for plant growth and development, which partially explains the physiological response of plants after environmental stress (Sun et al., 2016; Yamori et al., 2016). Studies have shown that K deficiency reduces mesophyll conductance, thereby reducing plant photosynthesis ( $\mathrm{Lu}$ et al., 2016a, 2019). High concentrations of salt decrease plant photosynthesis through osmotic stress and changes in related enzyme activities (Kong et al., 2017), but information on the effects of low concentrations of $\mathrm{Na}$ is limited. Changes in photosynthesis and chlorophyll fluorescence could partially explain how $\mathrm{K}$ and $\mathrm{Na}$ affect the physiological response of low-K lettuce.

Soluble sugars are the primary metabolites of photosynthesis. They play an important role in osmotic regulation with $\mathrm{K}$ and amino acids (Shabala and Cuin, 2007; Silva et al., 2010). In addition, sucrose is the carbohydrate that is translocated from photosynthesizing tissues to nonphotosynthetic sinks for use in metabolism and biosynthesis (Loka et al., 2018). The transport and distribution of carbohydrates are important physiological processes that affect plant growth.

Lettuce is a popular, healthy vegetable because it contains many bioactive phytochemicals (Vauzour et al., 2010), which are called secondary metabolites (SMs). In lettuce, SMs are mainly phenolic compounds and flavonoids. They possess the functions of antioxidant, antimicrobial, antifungal, antitoxic, and radical scavenging properties and affect the nutritional quality of plants (Hichri et al., 2011). The influence of mineral nutrition on concentrations of SMs in plants has been widely studied, but most studies have focused on $\mathrm{N}$ and $\mathrm{P}$. Phenolic compounds and flavonoids in lettuce are mainly the derivatives of caffeic acid and quercetin, and different varieties vary in their content of these compounds (Ouzounis et al., 2015; Yang et al., 2018b), which have strong antioxidant properties and are an important indicator of lettuce quality.

In this study, two cultivation methods, the EC control with $\mathrm{Na}$ replacing $\mathrm{K}$ at final stage (LKEC) and the QM method without the replacement of $\mathrm{Na}$ with $\mathrm{K}$ (LKQM), were used to cultivate low-K lettuce to explore the effects of $\mathrm{K}$ deficiency and $\mathrm{Na}$ accumulation on photosynthesis and concentrations of primary metabolites and SMs.

\section{Materials and Methods}

Experimental design. Experiments were conducted in an environment-controlled chamber at Chiba University, Matsudo Campus, from 4 Mar. to 9 Apr. 2019. Lettuce 
(Lactuca sativa L. cv. Frillice; Snow Brand Seed Co. Ltd., Sapporo, Japan) seeds were sown in sponge blocks measuring $2.3 \times 2.3 \times$ $2.7 \mathrm{~cm}$ and were transferred into a Nae Terrace growth chamber (Mitsubishi Chemical Agri Dream Co., Ltd., Tokyo, Japan) at a 16 -h photoperiod with $300 \pm 10 \mu \mathrm{mol} \cdot \mathrm{m}^{-2} \cdot \mathrm{s}^{-1}$ light intensity, $24{ }^{\circ} \mathrm{C}$ day $/ 20{ }^{\circ} \mathrm{C}$ night temperature, and $1000 \mathrm{ppm} \mathrm{CO}_{2}$ concentration until the seventh day after seeding (DAS). Next, lettuce seedlings with a uniform morphology were transplanted into another growth chamber with the same conditions as the previous one. Seedlings were planted on 26-hole, floating foam boards measuring $60 \times$ $30 \times 1 \mathrm{~cm}$ in 18 -L containers measuring of $60 \times 30 \times 10 \mathrm{~cm}$ from 7 to 14 DAS. Uniform lettuce plants were then moved to $60 \times 30 \times 1$ $\mathrm{cm}$ foam boards with six holes, and the boards were floated in the same containers. Groundwater, with a mineral composition of $0.8 \cdot \mathrm{mmol} \mathrm{L} \mathrm{L}^{-1} \mathrm{NO}_{3}-\mathrm{N}, 0.006 \mathrm{mmol} \cdot \mathrm{L}^{-1}$ $\mathrm{PO}_{4}-\mathrm{P}, 0.06 \mathrm{mmol} \cdot \mathrm{L}^{-1} \mathrm{~K}, 1.0 \mathrm{mmol} \cdot \mathrm{L}^{-1} \mathrm{Ca}$, $0.8 \mathrm{mmol} \cdot \mathrm{L}^{-1} \mathrm{Mg}$, and $0.6 \mathrm{mmol} \cdot \mathrm{L}^{-1} \mathrm{Na}$, was used in this experiment. Fresh air was supplied to the nutrient solution with an air pump, and the growth period was 35 DAS.

The time setting of the low-K treatment was as described by Ogawa et al. (2012), starting $7 \mathrm{~d}$ before harvest. Lettuce plants were cultivated using three nutrient solutions: 1) The control (CK) plants were supplied with half-strength Enshi formula solution $\left(8 \mathrm{mmol} \cdot \mathrm{L}^{-1} \mathrm{NO}_{3}-\mathrm{N}, 0.67 \mathrm{mmol} \cdot \mathrm{L}^{-1}\right.$ $\mathrm{PO}_{4}-\mathrm{P}, 4 \mathrm{mmol} \cdot \mathrm{L}^{-1} \mathrm{~K}, 2 \mathrm{mmol} \cdot \mathrm{L}^{-1} \mathrm{Ca}, 1$ mmol. $\mathrm{L}^{-1} \mathrm{Mg}$, 3ppm Fe, $0.5 \mathrm{ppm} \mathrm{B}, 0.5 \mathrm{ppm}$ $\mathrm{Mn}, 0.05 \mathrm{ppm} \mathrm{Zn}, 0.02 \mathrm{ppm} \mathrm{Cu}$, and 0.01 ppm Mo; Zhang et al., 2017) during the entire growth period with EC of $1.4 \mathrm{dS} \cdot \mathrm{m}^{-1}$ and $\mathrm{pH}$ of 7.0. 2) LKEC plants were supplied the same nutrient solution as the CK for days 7 to $28 \mathrm{DAS}$, and all the $\mathrm{K}$ in the Enshi solution was replaced with $\mathrm{Na}$ for the period of 28 to 35 DAS with an EC of $1.4 \mathrm{dS} \cdot \mathrm{m}^{-1}$ and $\mathrm{pH}$ of 7.0.3) LKQM plants were transplanted to the groundwater, and at 7, 14, and $28 \mathrm{DAS}$, quantitative chemical fertilizers were added to the groundwater following the LKQM recipe (Table 1) applied by Xu et al. (unpublished data), and the $\mathrm{pH}$ was adjusted to 7.0. The water level and EC of the nutrient solution in the container were adjusted every $3 \mathrm{~d}$. The EC values of the CK and LKEC treatments were adjusted every $3 \mathrm{~d}$ using a portable CM-31P EC meter (DKK-TOA, Japan). At the growth stage of 14 and 28 DAS, the nutrient solution was changed. The microelement concentrations in the nutrient solutions of these three treatments were the same, and each treatment was replicated three times.

Plant growth analysis. Six plants were harvested from each treatment at 28 and 35

Table 1. Nutrient amount required by low-K lettuce at different growth stages.

\begin{tabular}{lccccc}
\hline & \multicolumn{5}{c}{ Nutrient amount (mmol/plant/period) } \\
\cline { 2 - 6 } Days after seeding & $\mathrm{N}$ & $\mathrm{P}$ & $\mathrm{K}$ & $\mathrm{Ca}$ & $\mathrm{Mg}$ \\
\hline $7-14$ & 0.66 & 0.06 & 0.28 & 0.10 & 0.02 \\
$14-28$ & 5.06 & 0.42 & 2.35 & 0.72 & 0.21 \\
$28-35$ & 5.71 & 0.51 & 0.35 & 1.75 & 0.57 \\
\hline
\end{tabular}

DAS. The number of leaves, total leaf area, and FW of the plants were immediately evaluated. Total leaf areas were determined using an LI-300 leaf area meter (LI-COR Inc., Lincoln, NE). Specific leaf FW was the ratio of leaf $\mathrm{FW}$ to leaf area. Plant tissues were then dried at $80^{\circ} \mathrm{C}$ for at least $72 \mathrm{~h}$, and the DW of the plants were measured.

Potassium and sodium concentrations. The $\mathrm{K}$ and $\mathrm{Na}$ concentrations in the samples were determined based on the methodology of Maillard et al. (2015). Plant dry samples were ground to a fine powder with inox beads in a grinder (Wonder Blender WB-1, Osaka Chemical, Japan). Samples of $250 \mathrm{mg}$ DW of each plant were incinerated at $650{ }^{\circ} \mathrm{C}$ for $72 \mathrm{~h}$ in a muffle oven (Muffle Furnace FO300, Yamato Inc., Japan). Next, the ashes were dissolved in $3 \mathrm{~mL}$ of $2 \mathrm{~mol} \cdot \mathrm{L}^{-1} \mathrm{HCl}$, and deionized water was added to reach a fixed volume of $50 \mathrm{~mL}$. The filtered sample solutions were then diluted 10 times and measured using inductively coupled plasma optical emission spectrometry (ICP-OES, ICPE-9000, Shimadzu Inc., Japan).

Chlorophyll and carotenoid concentrations. Chlorophyll (Chl) and carotenoid (Car) concentrations were determined based on the methodology of Shen (1988). A leaf disk was taken from the third leaf from the outside of each plant using a puncher at 35 DAS and placed in a centrifuge tube, and then $10 \mathrm{~mL}$ of a mixed extract (ethanol:acetone:water $=$ 4.5:4.5:1) was added. The mixture was soaked in the dark to extract the pigments until the leaf disk was completely whitened. The absorption of the extract solution was measured at $440 \mathrm{~nm}, 645 \mathrm{~nm}$, and $663 \mathrm{~nm}$. The concentrations of $\mathrm{Chl} \mathrm{a}, \mathrm{Chl} \mathrm{b}$, and Car were determined using three equations $\left(\mu \mathrm{g} \cdot \mathrm{cm}^{-2}\right)$ :

$\mathrm{Chl} \mathrm{a}=\left(12.7 \times \mathrm{D}_{663}-2.69 \times \mathrm{OD}_{645}\right) \times 10 \mathrm{~V} / \mathrm{A}$

$\mathrm{Chl} \mathrm{b}=\left(22.9 \times \mathrm{OD}_{645}-4.68 \times \mathrm{OD}_{663}\right)$ $\times 10 \mathrm{~V} / \mathrm{A}$

$$
\begin{aligned}
\mathrm{Car}= & {\left[4.7 \times \mathrm{OD}_{440}-0.27 \times(\mathrm{Chl} \mathrm{a}+\mathrm{Chl} \mathrm{b})\right] } \\
& \times 10 \mathrm{~V} / \mathrm{A},
\end{aligned}
$$

where OD is the optical density, $V$ is the volume of the extracting solution (mL), and $A$ is the area of the leaf disk $\left(\mathrm{cm}^{2}\right)$.

Gas exchange parameters. The measurement of gas-exchange parameters conducted is described by Yamori et al. (2011), using a portable photosynthesis system (Li-6400XT, LI-COR Inc.). The third leaf from the outside was picked, and the net photosynthetic rate $\left(\mathrm{P}_{\mathrm{n}}\right)$, stomatal conductance $\left(g_{\mathrm{S}}\right)$, transpiration rate (Tr), and intercellular $\mathrm{CO}_{2}$ concentration (Ci) were measured at 33 DAS. Light was provided by red and blue light-emitting diodes (6400-02B, LI-COR Inc.). Photosynthetic photon flux density was measured at $300 \mu \mathrm{mol} \cdot \mathrm{m}^{-2} \cdot \mathrm{s}^{-1}$, and the leaf temperature, $\mathrm{CO}_{2}$ concentration, and relative humidity were $20{ }^{\circ} \mathrm{C} \pm 1{ }^{\circ} \mathrm{C}, 400 \pm 5 \mu \mathrm{mol} \cdot \mathrm{mol}^{-1}$, and $65 \% \pm 5 \%$, respectively.

Chlorophyll fluorescence parameters. Leaf chlorophyll fluorescence parameters were simultaneously measured at 34 DAS, using a portable photosynthesis system ( $\mathrm{Li}$ 6400XT, LI-COR Inc.), with an integrated fluorescence fluorometer (Li 6400-40 leaf chamber fluorometer, LI-COR Inc.), under ambient $\mathrm{CO}_{2}$ concentration and $21 \% \mathrm{O}_{2}$. The maximum quantum yield of the PS2 primary photochemistry ( $\mathrm{Fv} / \mathrm{Fm})$, efficiency of excitation energy capture by open PS2 reaction centers $\left(\mathrm{Fv}^{\prime} / \mathrm{Fm}^{\prime}\right)$, quantum yield of PS2 electron transport (PhiPS2), and photochemical quenching $(\mathrm{qP})$ were measured.

Soluble sugar concentration. Total soluble sugar was measured using the method described by Ibrahim et al. (2012), with modifications. Samples of $50 \mathrm{mg}$ leaf DW were placed in a test tube, to which $10 \mathrm{~mL}$ of $80 \%$ ethanol was added. This was placed in an $80^{\circ} \mathrm{C}$ water bath for $30 \mathrm{~min}$ and allowed to cool. Next, the supernatant was centrifuged at $4000 g_{n}$ for $3 \mathrm{~min}$. This step was repeated twice, and the supernatant was combined. A measure of $10 \mathrm{mg}$ of activated carbon was added to the supernatant and decolorized at $80{ }^{\circ} \mathrm{C}$ for $30 \mathrm{~min}$, and the volume was then adjusted to $25 \mathrm{~mL}$. After filtration, the soluble sugar concentration was determined using the anthrone-sulfuric acid method at $620 \mathrm{~nm}$.

Concentrations of total phenols and flavonoids. At 35 DAS, the third leaf from the outside was selected in this experiment. A sample of $0.5 \mathrm{~g}$ of lettuce sprouts was ground with liquid nitrogen, and $10 \mathrm{~mL}$ of $80 \%$ methanol was used for extraction. All samples were extracted in darkness for at least $90 \mathrm{~min}$ and then filtered and stored at $-20{ }^{\circ} \mathrm{C}$ for the next determination.

The concentration of total phenols (CTP) was determined using the Folin-Ciocalteu colorimetric assay according to the methodology proposed by Singleton et al. (1999), with modifications. A $0.5-\mathrm{mL}$ extract was added to $2.5 \mathrm{~mL}$ of reaction solution, which contained $0.4 \mathrm{~mL}$ of Folin phenol, and reacted for $3 \mathrm{~min}$. Then, $10 \mathrm{~mL}$ of $10 \% \mathrm{Na}_{2}$ $\mathrm{CO}_{3}$ was added, and the absorption at $765 \mathrm{~nm}$ was measured. The results were expressed as milligrams chlorogenic acid equivalents (CGE) per gram FW.

The concentration of total flavonoids (CTF) was determined using the methods described by Zhishen et al. (1999). First, $0.5 \mathrm{~mL}$ of extract was added to $1 \mathrm{~mL}$ of $5 \% \mathrm{NaNO}_{2}, 1$ $\mathrm{mL}$ of $10 \% \mathrm{Al}\left(\mathrm{NO}_{3}\right)_{3}$, and $4 \mathrm{~mL}$ of $2 \mathrm{~mol} \cdot \mathrm{L}^{-1}$ $\mathrm{NaOH}$ and mixed and reacted for $15 \mathrm{~min}$. Then, the absorption at $510 \mathrm{~nm}$ was measured. The CTF was expressed as milligrams of rutin equivalents (RTE) per gram FW.

DPPH (2,2-diphenyl-1-picryl-hydrazylhydrate) assay. Antioxidant activity using the DPPH radical was determined based on the methodology of Viacava et al. (2015). A 
0.25-mL sample of extract was mixed with 1 $\mathrm{mL}$ of $100 \mu \mathrm{m}$ methanol DPPH solution. The mixtures were immediately shaken and allowed to stand at a refrigeration temperature of $2{ }^{\circ} \mathrm{C}$ in the dark. The decrease in absorption at $517 \mathrm{~nm}$ was measured after $60 \mathrm{~min}$, and DPPH radical scavenging activity was expressed as $\mathrm{mg}$ of Trolox equivalents per $100 \mathrm{~g} \mathrm{FW}$.

Secondary metabolite concentrations. At 35 DAS, the third leaves from the outside were freeze-dried at $10{ }^{\circ} \mathrm{C}$ for $5 \mathrm{~d}$ in a freeze-dry machine (DRC-1000, FDU-2100; EYELA Inc., Tokyo, Japan). The dried samples were crushed into powder and filtered through a sieve $(1 \mathrm{~mm})$. A 200-mg sample of a dry leaf was weighed and transferred to a $5-\mathrm{mL}$ Eppendorf tube (Hamburg, Germany). Then, $2.5 \mathrm{~mL}$ of methanol was added, mixed for $15 \mathrm{~min}$ at $1000 \mathrm{rpm}$ at $20{ }^{\circ} \mathrm{C}$ using an Eppendorf ThermoMixer $\mathrm{C}$, and centrifuged for $5 \mathrm{~min}$. Next, $2.5 \mathrm{~mL}$ of methanol was added to the residue, and the same extract procedure was performed. The combined extracts were transferred to a $5-\mathrm{mL}$ volumetric flask and diluted with methanol to a $5 \mathrm{~mL}$ total volume. The solution was then filtered through a $0.22-\mu$ m nylon syringe filter (Shimadzu GLC Ltd., Tokyo, Japan).

Analysis of chicoric acid (CC) concentration was conducted using high-performance liquid chromatography (HPLC). The HPLC system was composed of a Shimadzu LC20A Prominence system equipped with a SIL-20AC autosampler and an SPD-20A PDA detector using LabSolutions software (Shimadzu, Kyoto, Japan). Specific HPLC conditions were followed for the analysis of CC: a $5-\mu \mathrm{m}, 4.6 \times 150 \mathrm{~mm}$ TSKgel ODS$80 \mathrm{~T}_{\mathrm{M}}$ column (Tosoh, Tokyo, Japan) was used, at a temperature of $40{ }^{\circ} \mathrm{C}$, flow rate of $1.0 \mathrm{~mL} \cdot \mathrm{min}^{-1}$, run time of $15 \mathrm{~min}$, detector wavelength of $330 \mathrm{~nm}$, mobile phase of $15 \%$ acetonitrile $/ 0.1 \%$ formic acid, and injection volume of $10 \mu \mathrm{L}$.

The concentrations of caffeic acid (CF), chlorogenic acid (CG), rutin (RT), and isoquercitrin (IQ) were measured using liquid chromatography-mass spectrometry (LCMS), which was conducted according to Nguyen et al. (2019), with modifications. An LC-MS-2020 mass spectrometer equipped with an electrospray ionization (ESI) source, operating in negative mode, was used for the identification and quantification of $\mathrm{CF}, \mathrm{CG}, \mathrm{RT}$, and IQ. The HPLC analysis of $\mathrm{CF}, \mathrm{CG}, \mathrm{RT}$, and IQ was conducted using an XBridge BEH C18 column $(3.5 \mu \mathrm{m}, 2.1 \times$ $150 \mathrm{~mm}$, Waters, MA) at a temperature of $35{ }^{\circ} \mathrm{C}$, flow rate of $0.2 \mathrm{~mL} \cdot \mathrm{min}^{-1}$, and an injection volume of $1 \mu \mathrm{L}$. The elution was conducted with a mobile phase consisting of solvent $\mathrm{A}(0.1 \%$ formic acid, $v / v)$ and solvent $\mathrm{B}(100 \%$ acetonitrile) using a gradient flow of $10 \%$ to $20 \% \mathrm{~B}$ at 0 to $5 \mathrm{~min}, 20 \% \mathrm{~B}$ at 5 to 10 $\mathrm{min}$, and $10 \% \mathrm{~B}$ at 10 to $20 \mathrm{~min}$. The eluent was passed to the ESI source, and a capillary voltage of $3.5 \mathrm{kV}$ was used in the negative ion mode. Nitrogen was used as the drying gas with a flow rate of $15 \mathrm{~L} \cdot \mathrm{min}^{-1}$ and nebulizing gas with a flow rate of $1.5 \mathrm{~L} \cdot \mathrm{min}^{-1}$. The desolvation line temperature was set at
$250{ }^{\circ} \mathrm{C}$. The ion trap was operated in full scan mode from $\mathrm{m} / \mathrm{z} 50$ to 1000 and selected ion monitoring mode with $m / z 179,353,609$, and 463 for a molecular ion $[\mathrm{M}-\mathrm{H}]^{-}$of $\mathrm{CF}$, $\mathrm{CG}, \mathrm{RT}$, and IQ, respectively.

Statistical analysis. A one-way analysis of variance was calculated using SPSS 17.0 software (SPSS Inc., Chicago, IL), and the mean values were compared using Tukey's honestly significant difference test $(P<0.05)$. Data were represented as the mean \pm standard errors (SE). Graphics were created using GraphPad Prism 5 (GraphPad, San Diego, CA).

\section{Results}

Plant growth. Both LKEC and LKQM treatments exerted negative effects on plant growth. However, no significant difference was found between the LKEC and LKQM treatments in measurements of plant growth. Compared with CK, the LKEC and LKQM treatments decreased plant FW, DW, and leaf area by nearly $24 \%, 22 \%$, and $21 \%$, respectively (Table 2). The number of leaves and specific leaf area were unaffected by the two low-K treatments.

Potassium and sodium concentrations. At 28 DAS, there was no significant difference in concentrations of $\mathrm{K}$ and $\mathrm{Na}$ between $\mathrm{CK}$, LKEC, and LKQM treatments. At 35 DAS, there was no change in concentrations of $\mathrm{K}$ and $\mathrm{Na}$ in the CK, compared with the 28 DAS, whereas in the lettuce with LKEC and LKQM treatments, the $\mathrm{K}$ concentration decreased and $\mathrm{Na}$ concentration increased.

At 35 DAS, the $\mathrm{K}$ concentration in the plants with LKEC and LKQM treatments decreased by $65 \%$ compared with the CK about. No significant difference was found in the $\mathrm{K}$ levels between the two $\mathrm{K}$ treatments (Fig. 1A). Compared with the CK, the LKEC and LKQM treatments increased the Na concentration by $245 \%$ and $103 \%$, respectively (Fig. 1B).

Photosynthesis-related characteristics. The two low-K treatments did not affect the photosynthesis parameters, such as the $\mathrm{P}_{\mathrm{n}}, g_{\mathrm{S}}$, $\mathrm{Ci}$, and $\operatorname{Tr}$ (Table 3 ). In addition, there was no significant difference between the three treatments in chlorophyll fluorescence parameters, including $\mathrm{Fv} / \mathrm{Fm}, \mathrm{Fv}^{\prime} / \mathrm{Fm}^{\prime}$, PhiPS2, and qP (Table 4).

$\mathrm{Chl} \mathrm{a}$ and $\mathrm{b}$ concentrations and the $\mathrm{Chl}$ a to $\mathrm{Chl} b$ ratio were also unaffected by LKEC and LKQM treatments, whereas the Car concentration was increased compared with the CK. No significant difference was found between the LKEC and LKQM treatments for photosynthetic pigment concentrations (Table 5).

Compared with CK, LKEC and LKQM treatments increased the soluble sugar concentration by nearly $110 \%$, whereas no significant difference appeared between them (Fig. 2).

Concentrations of total phenols and flavonoids. CTP was increased by the low-K treatments. The LKEC treatment showed a more substantial increase, of $\approx 20 \%$, compared with CK, whereas CTP of the LKQM treatment increased by $\approx 11 \%$ (Fig. 3A). CTF showed the same trend as CTP, with a higher gain: the LKEC treatment increased by $82 \%$, and the LKQM treatment increased by $68 \%$ (Fig. 3B).

Secondary metabolite concentrations. The lettuce under the LKEC treatment consistently contained the highest concentration

Table 2. Effects of the LKEC and LKQM treatments on the lettuce plant FW, DW, number of leaves, leaf area and specific leaf area.

\begin{tabular}{lrrrrr}
\hline Treatments & Plant FW $(\mathrm{g})$ & Plant DW $(\mathrm{g})$ & No. of leaves & Leaf area $\left(\mathrm{dm}^{2}\right)$ & $\begin{array}{r}\text { Specific leaf } \\
\text { area }\left(\mathrm{g} \cdot \mathrm{dm}^{-2}\right)\end{array}$ \\
\hline CK & $106.8 \pm 8.3 \mathrm{a}^{\mathrm{z}}$ & $4.01 \pm 0.50 \mathrm{a}$ & $13.0 \pm 0.8 \mathrm{a}$ & $10.64 \pm 0.55 \mathrm{a}$ & $9.11 \pm 0.80 \mathrm{a}$ \\
LKEC & $81.2 \pm 6.3 \mathrm{~b}$ & $3.41 \pm 0.30 \mathrm{~b}$ & $13.7 \pm 0.5 \mathrm{a}$ & $8.44 \pm 0.38 \mathrm{~b}$ & $8.94 \pm 0.65 \mathrm{a}$ \\
LKQM & $81.1 \pm 4.4 \mathrm{~b}$ & $3.40 \pm 0.17 \mathrm{~b}$ & $13.6 \pm 0.5 \mathrm{a}$ & $8.32 \pm 0.43 \mathrm{~b}$ & $8.85 \pm 0.66 \mathrm{a}$ \\
\hline
\end{tabular}

${ }^{\mathrm{z}}$ Each value is the mean $\pm \mathrm{SE}$ of three replicates. Different letters indicate significant differences at $P<0.05$, according to Tukey's honestly significant difference test.

$\mathrm{CK}=$ control; $\mathrm{DW}=$ dry weight; $\mathrm{FW}=$ fresh weight LKEC = low potassium with $\mathrm{K}$ replaced by $\mathrm{Na}$; $\mathrm{LKQM}=$ low potassium treatment based on quantitative nutrient management.
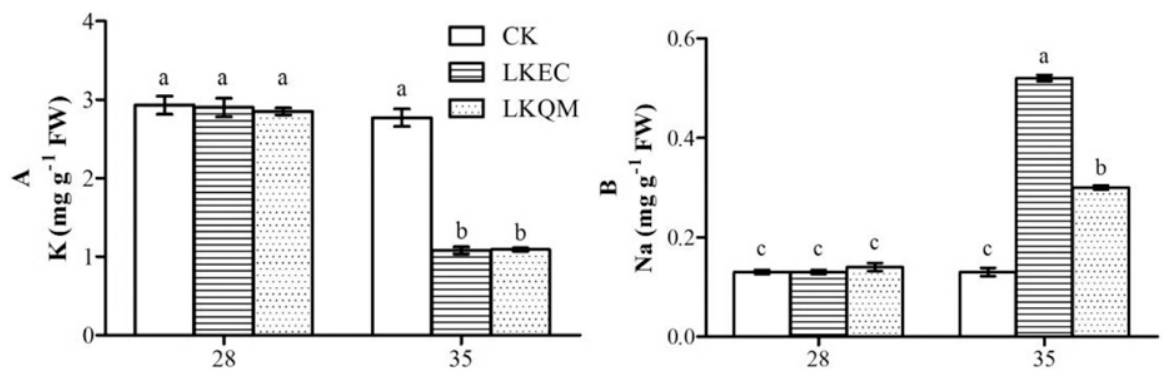

Fig. 1. Effects of the LKEC and LKQM treatments on the $\mathrm{K}(\mathbf{A})$ and $\mathrm{Na}(\mathbf{B})$ concentrations of lettuce plants at 28 and 35 DAS. Data represent the mean $\pm \mathrm{SE}(\mathrm{n}=3)$. Different letters indicate significant differences at $P<0.05$, according to Tukey's honestly significant difference test. CK $=$ control; LKEC $=$ low potassium with $\mathrm{K}$ replaced by $\mathrm{Na}$; $\mathrm{LKQM}=$ low potassium treatment based on quantitative nutrient management. 
Table 3. Effects of the LKEC and LKQM treatments on leaf photosynthesis.

\begin{tabular}{lcccc}
\hline Treatments & $\mathrm{P}_{\mathrm{n}}\left(\mu \mathrm{mol} \mathrm{CO} \mathrm{CO}_{2} / \mathrm{m}^{2} / \mathrm{s}\right)$ & $g_{\mathrm{S}}\left(\mathrm{mol} \mathrm{H}_{2} \mathrm{O} / \mathrm{m}^{2} / \mathrm{s}\right)$ & $\mathrm{Ci}\left(\mu \mathrm{mol} \mathrm{CO} \mathrm{CO}_{2} / \mathrm{mol}\right)$ & $\operatorname{Tr}\left(\mathrm{mol} \mathrm{H}_{2} \mathrm{O} / \mathrm{m}^{2} / \mathrm{s}\right)$ \\
\hline CK & $5.54 \pm 0.27 \mathrm{a}^{2}$ & $0.201 \pm 0.007 \mathrm{a}$ & $350 \pm 5 \mathrm{a}$ & $1.74 \pm 0.11 \mathrm{a}$ \\
LKEC & $5.47 \pm 0.23 \mathrm{a}$ & $0.191 \pm 0.009 \mathrm{a}$ & $355 \pm 7 \mathrm{a}$ & $1.70 \pm 0.06 \mathrm{a}$ \\
LKQM & $5.43 \pm 0.10 \mathrm{a}$ & $0.189 \pm 0.013 \mathrm{a}$ & $350 \pm 2 \mathrm{a}$ & $1.68 \pm 0.12 \mathrm{a}$ \\
\hline
\end{tabular}

${ }^{\mathrm{z}}$ Each value is the mean $\pm \mathrm{SE}$ of three replicates. Different letters indicate significant differences at $P<0.05$, according to Tukey's honestly significant difference test.

$\mathrm{CK}=$ control; $\mathrm{LKEC}=$ low potassium with $\mathrm{K}$ replaced by $\mathrm{Na} ; \mathrm{LKQM}=$ low potassium treatment based on quantitative nutrient management; $\mathrm{P}_{\mathrm{n}}=$ net photosynthetic rate; $g_{\mathrm{S}}=$ stomatal conductance; $\mathrm{Ci}=$ intercellular $\mathrm{CO}_{2}$ concentration; $\mathrm{Tr}=$ transpiration rate.

Table 4. Effects of the LKEC and LKQM treatments on leaf chlorophyll fluorescence.

\begin{tabular}{lcccc}
\hline Treatments & $\mathrm{Fv} / \mathrm{Fm}$ & $\mathrm{Fv}^{\prime} / \mathrm{Fm}^{\prime}$ & PhiPS2 & $\mathrm{qP}$ \\
\hline CK & $0.811 \pm 0.013 \mathrm{a}^{\mathrm{z}}$ & $0.569 \pm 0.021 \mathrm{a}$ & $0.222 \pm 0.010 \mathrm{a}$ & $0.343 \pm 0.010 \mathrm{a}$ \\
LKEC & $0.820 \pm 0.005 \mathrm{a}$ & $0.565 \pm 0.009 \mathrm{a}$ & $0.228 \pm 0.007 \mathrm{a}$ & $0.349 \pm 0.012 \mathrm{a}$ \\
LKQM & $0.823 \pm 0.004 \mathrm{a}$ & $0.558 \pm 0.033 \mathrm{a}$ & $0.211 \pm 0.007 \mathrm{a}$ & $0.341 \pm 0.018 \mathrm{a}$ \\
\hline
\end{tabular}

${ }^{\mathrm{z}}$ Each value is the mean $\pm \mathrm{SE}$ of three replicates. Different letters indicate significant differences at $P<0.05$, according to Tukey's honestly significant difference test.

$\mathrm{CK}=$ control; $\mathrm{DW}=$ dry weight; $\mathrm{Fv} / \mathrm{Fm}=$ maximum quantum yield of the PS2 primary photochemistry; $\mathrm{Fv}^{\prime} / \mathrm{Fm}^{\prime}=$ efficiency of excitation energy capture by open PS2 reaction centers; $\mathrm{FW}=$ fresh weight; $\mathrm{LKEC}=$ low potassium with $\mathrm{K}$ replaced by $\mathrm{Na}$; $\mathrm{LKQM}=$ low potassium treatment based on quantitative nutrient management; PhiPS2 = quantum yield of PS2 electron transport.

Table 5. Effects of the LKEC and LKQM treatments on chlorophyll a (Chl a), chlorophyll b (Chl b), and carotenoid (Car) concentrations and the $\mathrm{Chl}$ a to $\mathrm{Chl} b$ ratio $(\mathrm{Chl} \mathrm{a} / \mathrm{b})$ of lettuce.

\begin{tabular}{lcccc}
\hline Treatments & Chl a $\left(\mu \mathrm{g} \cdot \mathrm{cm}^{-2}\right)$ & Chl b $\left(\mu \mathrm{g} \cdot \mathrm{cm}^{-2}\right)$ & Car $\left(\mu \mathrm{g} \cdot \mathrm{cm}^{-2}\right)$ & Chl a/b \\
\hline CK & $18.5 \pm 1.3 \mathrm{a}^{\mathrm{z}}$ & $9.2 \pm 0.7 \mathrm{a}$ & $2.2 \pm 0.2 \mathrm{~b}$ & $2.02 \pm 0.07 \mathrm{a}$ \\
LKEC & $18.2 \pm 0.6 \mathrm{a}$ & $8.9 \pm 0.7 \mathrm{a}$ & $2.6 \pm 0.2 \mathrm{a}$ & $2.05 \pm 0.09 \mathrm{a}$ \\
LKQM & $17.5 \pm 0.7 \mathrm{a}$ & $8.9 \pm 0.4 \mathrm{a}$ & $2.6 \pm 0.1 \mathrm{a}$ & $1.97 \pm 0.06 \mathrm{a}$ \\
\hline
\end{tabular}

${ }^{\mathrm{z}}$ Each value is the mean \pm SE of three replicates. Different letters indicate significant differences at $P<0.05$, according to Tukey's honestly significant difference test.

$\mathrm{CK}=$ control; $\mathrm{LKEC}=$ low potassium with $\mathrm{K}$ replaced by $\mathrm{Na} ; \mathrm{LKQM}=$ low potassium treatment based on quantitative nutrient management.

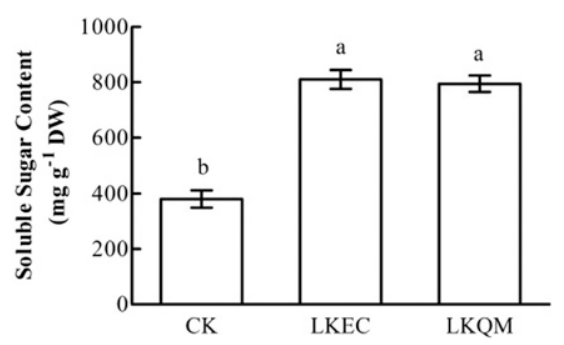

Fig. 2. Effects of the LKEC and LKQM treatments on the soluble sugar concentration of lettuce. Data represent the mean $\pm \mathrm{SE}(\mathrm{n}=3)$. Different letters indicate significant differences at $P<$ 0.05 , according to Tukey's honestly significant difference test. $\mathrm{CK}=$ control; $\mathrm{LKEC}=$ low potassium with $\mathrm{K}$ replaced by $\mathrm{Na}$; $\mathrm{LKQM}=$ low potassium treatment based on quantitative nutrient management.

of SMs, which were $67 \%, 92 \%, 23 \%, 32 \%$, and $152 \%$ higher for RT, CG, CF, IQ, and $\mathrm{CC}$, respectively, than the control. The RT, $\mathrm{CG}$, and CC concentrations in the LKQM plants were also higher than the control by $36 \%, 28 \%$, and $121 \%$, respectively. The CF and IQ concentrations between the LKQM and $\mathrm{CK}$ treatments showed no significant difference (Table 6).

Antioxidant activity. Compared with CK, the antioxidant activity of the plants was significantly enhanced by the LKEC and LKQM treatments (Fig. 4). The Trolox equivalents in the LKEC treatment were $61 \%$ higher than the control, whereas in the LKQM treatment, they were $45 \%$ higher than the control.

\section{Discussion}

Effects of low-K treatments on photosynthesis and plant growth. The $\mathrm{K}$ concentration of lettuce treated with both LKEC and LKQM was close to $100 \mathrm{mg} \cdot \mathrm{g}^{-1} \mathrm{FW}$ (Fig. 1), which met the criteria for low-K lettuce. However, the FW, DW, and leaf area of lettuce plant was decrease in these two treatments compared with the CK (Table 2). Ogawa et al. (2012) found that with the LKQM method, K concentration in leaf vegetable decreased to $30 \%$ to $40 \%$ compared with CK. Other similar experiments found that different low-K treatment methods and lettuce varieties affect the yield and quality of low-K lettuce (Chang and Fang, 2019; Ogawa et al., 2014; Renna et al., 2018; Yoshida et al., 2016; Zhang et al., 2016). Thus, the growth limitation of low-K lettuce in this study was understandable.

The absence of significant differences in the growth indicators, photosynthetic indicators, and soluble sugars between the LKEC and LKQM treatments indicates that the two low-K treatments had the same effect on the growth of the studied lettuce plants. Compared with $\mathrm{CK}$, the yield and $\mathrm{K}$ concentration in the lettuces from the two low-K treatments decreased by $20 \%$ and $65 \%$, respectively, whereas the mean of $P_{n}$ did not decline. However, the soluble sugar concentration in low-K treatments increased by $110 \%$ compared with CK. Plants per unit mass fixed an equal amount of $\mathrm{CO}_{2}$ through photosynthesis, and a large amount of soluble sugars existed in the low-K lettuce, resulting in carbon not being fully used for cell growth, division, and differentiation. This might explain why the biomass of low-K lettuce decreased with constant photosynthesis. A possible reason for soluble sugar accumulation in low-K lettuce is that soluble sugars could have compensated for the osmotic pressure gap after $\mathrm{K}$ deficiency because $\mathrm{K}$ is the main osmotic adjustment substance of plants (Cakmak et al., 1994; Hafsi et al., 2014; Talbott and Zeiger, 1996). In rice, when the $\mathrm{K}$ transporter-related gene $O s H A K 1$ is knocked out, the synthesis and transport of sucrose are reduced, but the concentration of sucrose in leaves was increased (Chen et al., 2018). In cotton, $\mathrm{K}$ deficiency also causes an increase in sucrose and starch in leaves $(\mathrm{Hu}$ et al., 2018). Therefore, the accumulation of soluble sugar might slow the growth of low-K lettuce. In addition to soluble sugars, amino acids and other cations are also important components in maintaining plant vacuolar osmotic pressure, and they compensate for reduced osmotic pressure in the absence of $\mathrm{K}$ (Hu et al., 2018; Wakeel et al., 2011; Wang et al., 2012b). The increased Na concentration in lettuce leaves in the LKEC and LKQM treatments indicated that $\mathrm{Na}$ was also involved in the compensation of osmotic pressure.

The leaf $\mathrm{P}_{\mathrm{n}}$ can also be affected by $\mathrm{K}(\mathrm{Lu}$ et al., 2016a, 2019). However, in this study, the mean $\mathrm{P}_{\mathrm{n}}$ did not decline. Other critical components of photosynthesis, such as $g_{\mathrm{S}}, \mathrm{Ci}$, $\mathrm{Tr}, \mathrm{Fv} / \mathrm{Fm}, \mathrm{Fv}^{\prime} / \mathrm{Fm}^{\prime}$, PhiPS2, $\mathrm{qP}$, and the chlorophyll concentration, were also unaffected (Tables 3 and 4). This finding might be because the reduced osmotic pressure, as a result of less $\mathrm{K}$, was compensated for by substances such as soluble sugars, whereas $\mathrm{K}$, which was controlled by $g_{\mathrm{S}}$ and related enzyme activity, was unaffected. This phenomenon can be determined by the degree of $\mathrm{K}$ deficiency. Quantitative limitation analysis found that $0.98 \% \mathrm{~K}$ did not affect the net $\mathrm{CO}_{2}$ assimilation rate, compared with $1.66 \%$ of $\mathrm{K}$ in the control treatment in Brassica napus L. (Lu et al., 2016b). In soybean (cv. Spencer), K deficiency limited growth traits rather than the photosynthetic processes at a moderate $\mathrm{K}$ deficiency of $1 \% \mathrm{~K}$ concentration in the leaf (Singh and Reddy, 2017). These results were consistent with our finding that growth of low-K lettuce was limited while photosynthesis was constant. This might be because the decline of assimilation accumulation and biomass had already occurred before leaf photosynthesis was affected by K deficiency (Edward et al., 2010; Wang et al., 2012a).

Here we propose a hypothesis about the physiological response of low-K lettuce. The $\mathrm{K}$ intake was decreased but photosynthesis 

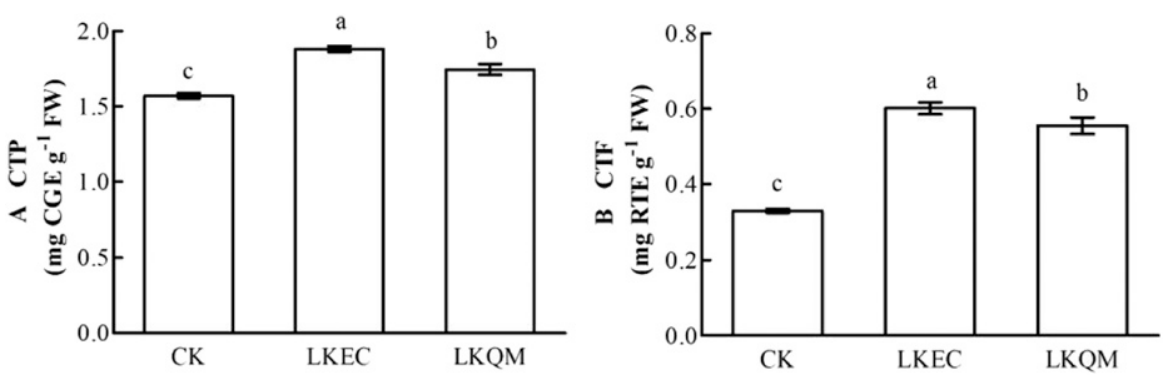

Fig. 3. Effects of the LKEC and LKQM treatments on the CTP (A) and CTF (B) of lettuce. Data represent the mean \pm SE $(n=3)$. Different letters indicate significant differences at $P<0.05$, according to Tukey's honestly significant difference test. $\mathrm{CK}=$ control; $\mathrm{LKEC}=$ low potassium with $\mathrm{K}$ replaced by $\mathrm{Na}$; $\mathrm{LKQM}=$ low potassium treatment based on quantitative nutrient management.

Table 6. Effects of LKEC and LKQM treatments on rutin (RT), chlorogenic acid (CG), caffeic acid (CF), isoquercitrin (IQ), and chicoric acid (CC) concentrations $\left(\mu \mathrm{g} \cdot \mathrm{g}^{-1} \mathrm{DW}\right)$ in lettuce.

\begin{tabular}{lccccc}
\hline Treatments & RT & CG & CF & IQ & CC \\
\hline CK & $0.49 \pm 0.03 \mathrm{c}^{\mathrm{z}}$ & $32.1 \pm 1.7 \mathrm{c}$ & $0.35 \pm 0.02 \mathrm{~b}$ & $0.47 \pm 0.02 \mathrm{~b}$ & $144 \pm 10 \mathrm{c}$ \\
LKEC & $0.82 \pm 0.04 \mathrm{a}$ & $61.8 \pm 1.8 \mathrm{a}$ & $0.43 \pm 0.01 \mathrm{a}$ & $0.62 \pm 0.01 \mathrm{a}$ & $362 \pm 12 \mathrm{a}$ \\
LKQM & $0.67 \pm 0.04 \mathrm{~b}$ & $41.0 \pm 2.0 \mathrm{~b}$ & $0.36 \pm 0.02 \mathrm{~b}$ & $0.53 \pm 0.02 \mathrm{~b}$ & $317 \pm 11 \mathrm{~b}$ \\
\hline
\end{tabular}

${ }^{\mathrm{z}}$ Each value is the mean $\pm \mathrm{SE}$ of three replicates. Different letters indicate significant differences at $P<0.05$ according to Tukey's honestly significant difference test.

$\mathrm{CK}=$ control; $\mathrm{DW}=$ dry weight; $\mathrm{LKEC}=$ low potassium with $\mathrm{K}$ replaced by $\mathrm{Na} ; \mathrm{LKQM}=$ low potassium treatment based on quantitative nutrient management.

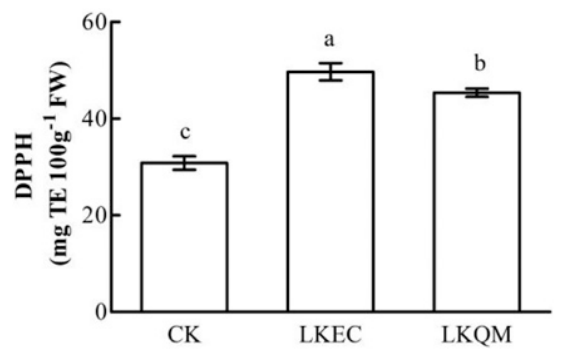

Fig. 4. Effects of the LKEC and LKQM treatments on the antioxidant activity of lettuce. Data represent mean $\pm \mathrm{SE}(\mathrm{n}=3)$. Different letters indicate significant differences at $P<0.05$, according to Tukey's honestly significant difference test. $\mathrm{CK}=$ control; $\mathrm{LKEC}=$ low potassium with $\mathrm{K}$ replaced by $\mathrm{Na}$; LKQM = low potassium treatment based on quantitative nutrient management.

was not reduced. The $\mathrm{K}$ concentration in the vacuole is reduced firstly, which leads to a decrease in the osmotic pressure of the cell. Therefore, the soluble sugar, amino acids, and cations are increased to maintain osmotic pressure, leading to a decline in the translocation of sucrose and amino acids, which inhibits the growth of lettuce plant.

Effects of potassium deficiency and sodium accumulation on plant secondary metabolite concentrations. The concentrations of total phenol (Fig. 3A) and flavonoid (Fig. 3B) in low-K treatments were higher than those of the control. In our study, the RT, CG, CA, IQ, and $\mathrm{CC}$ were also identified (Table 6). The concentrations of SMs in low-K lettuce plants were higher than that of the control. Interestingly, Car concentration in low-K lettuce was also higher than that of the control (Table 4) because the Cars are also a kind of SM, providing protection when plants are overexposed to free radical detoxification (Lattanzio et al., 2006). A large number of experiments have been reported in which the nutrient deficiencies of plants were characterized by an accumulation of flavonoids, such as the anthocyanins (Yang et al., 2018a). In lupins (Lupinus angustifolius), K deficiency resulted in low-quality seeds with high alkaloid concentrations, such as angustifoline, lupanine, and 13-hydroxylupanine (Gremigni et al., 2001). In the Chrysanthemum morifolium, $\mathrm{K}$ deficiency increased the content of total flavonoids in leaves at the vegetative stage, while it decreased in leaves and flowers at the reproductive stage (Liu et al., 2010). A reasonable explanation might be that some metabolic enzyme activities were changed in low-K plants, which caused the changing of metabolites. In addition, $\mathrm{K}$ was an essential element for plants, and this nutritional stress of $\mathrm{K}$ promotes the production of stress metabolites (Liu et al., 2010).

An interesting finding was that the concentration of SMs in lettuce plants in the LKEC treatment was higher than that in the LKQM treatment (Figs. 3 and 4; Table 5). This finding might be due to the higher concentration of $\mathrm{Na}$ in the nutrient solution of LKEC, which was nearly 6 mM. Substantial research on the effects of $\mathrm{Na}$ on concentrations of plant SMs has been conducted (Menezes-Benavente et al., 2004; Minh et al., 2016). However, most of this research has focused on salt stress in cases where the $\mathrm{Na}$ concentration around the root zone reached 100 to $200 \mathrm{~mm}$. It has been found that in the long-term treatment of $5 \mathrm{~mm} \mathrm{NaCl}$, the total carotenoids were increased, whereas the phenolic concentration remained stable in romaine lettuce (Kim et al., 2008). Salt stress often created both ionic and osmotic stress in plants, resulting in the accumulation or decrease of specific SMs in plants (Mahajan and Tuteja, 2005). In this research, the Na might only perform its ionic function. Furthermore, the low concentration of $\mathrm{Na}$ in the solution did not affect plant growth, photosynthesis, or primary metabolites, but it affected the SMs, which proved that SMs were more sensitive to changes in the environment.

$\mathrm{CG}$ and $\mathrm{CC}$ were the main component of phenols in lettuce and were the CF derivatives (Ouzounis et al., 2015). CG and CC were the two main products in this metabolism, and CF was the intermediate product (Murthy et al., 2014). RT and IQ were the main flavonoids in lettuce and were the different products in the same metabolism (Verhoeyen et al., 2002). These products varied widely. $\mathrm{CC}$ concentration in lettuce was the highest among the individual phenolic compounds, and the increase caused by $\mathrm{K}$ and $\mathrm{Na}$ was also the largest. CF and IQ were hardly affected by $\mathrm{K}$ deficiency, whereas they were affected by $\mathrm{Na}$. These differences indicate that $\mathrm{K}$ and $\mathrm{Na}$ affected not only the concentration of SMs but also the proportion of different metabolites. This might be because $\mathrm{K}$ deficiency and $\mathrm{Na}$ stress had different effects on different enzymes in the biosynthetic phenolic pathway (Wang et al., $2012 b$ ). In conclusion, both $\mathrm{Na}$ and $\mathrm{K}$ have important effects at the level of SMs.

The nutritional value of low-K. In either LKEC or LKQM treatment, as the K concentration decreased, other components were increased, such as soluble sugars, $\mathrm{Na}$, phenols, and flavonoids (Figs. 1-4). These components also increased the burden on the kidney of dialysis patients (Nowak et al., 2017; Uribarri, 2018). The antioxidant activity of lettuce with LKEC treatment was highest, and it is considered good for human health. However, most of the sources of this antioxidant activity are polyphenols, and they will accumulate and show the indubitable potentially toxic effects for dialysis patients (Malejane et al., 2018; Nowak et al., 2017).

Generally speaking, the LKQM method was considered better because it reduced the $\mathrm{Na}$ concentration in low-K lettuce, as we expected. However, the results on SMs were conflicting. So, as a functional food, the nutritional value of low-K lettuce should be further evaluated.

\section{Conclusion}

After two low-K treatments (LKEC and LKQM) in this study, the yield of lettuce decreased without any photosynthesis change. The soluble sugar concentration increased, which was thought to be the main reason for the reduced biomass of low-K lettuce due to the decline in carbon source used for other organ growth. K deficiency also increased the concentration of SMs in lettuce. Furthermore, higher concentration of $\mathrm{Na}$ in the nutrient solution of the LKEC treatment also caused 
an effect on the concentration of SMs, and $\mathrm{Na}$ and $\mathrm{K}$ had different effects on different compounds.

\section{Literature Cited}

Cakmak, I., C. Hengeler, and H. Marschner. 1994. Changes in phloem export of sucrose in leaves in response to phosphorus, potassium and magnesium deficiency in bean plants. J. Expt. Bot. 45:1251-1257.

Chang, H.Y. and W. Fang. 2019. Study on cultivated low-potassium lettuce (Lactuca sativa L.) in plant factory. TARI 214:161-172.

Chen, G., Y. Zhang, B. Ruan, L. Guo, D. Zeng, Z. Gao, L. Zhu, J. Hu, D. Ren, L. Yu, G. Xu, and Q. Qian. 2018. OsHAK1 controls the vegetative growth and panicle fertility of rice by its effect on potassium-mediated sugar metabolism. Plant Sci. 274:261-270.

Chérel, I., E. Michard, N. Platet, K. Mouline, C. Alcon, H. Sectenac, and J.B. Thibaud. 2002. Physical and functional interaction of the arabidopsis $\mathrm{K}^{+}$channel AKT2 and phosphatase AtPP2CA. Plant Cell 14:1133-1146.

Edward, G., J.M. Lionel, C. Julie, P. Sylvain, and D. Michael. 2010. Changes in plant morphology and dry matter partitioning caused by potassium deficiency in Gossypium hirsutum (L.). Environ. Expt. Bot. 67:451-459.

Gremigni, P., M.T.F. Wong, N.K. Edwards, D. Harris, and J. Hamblin. 2001. Potassium nutrition effects on seed alkaloid concentrations, yield and mineral content of lupins (Lupinus angustifolius). Plant Soil 234:131-142.

Hafsi, C., A. Debez, and C. Abdelly. 2014. Potassium deficiency in plants: Effects and signaling cascades. Acta Physiol. Plant. 36:1055-1070.

Hichri, I., F. Barrieu, J. Bogs, C. Kappel, S. Delrot, and V. Lauvergeat. 2011. Recent advances in the transcriptional regulation of flavonoid biosynthetic pathway. J. Expt. Bot. 62:2465-2483.

Hu, W., D.A. Loka, T.R. Fitzsimons, Z. Zhou, and D.M. Oosterhuis. 2018. Potassium deficiency limits reproductive success by altering carbohydrate and protein balances in cotton (Gossypium hirsutum L.). Environ. Expt. Bot. 145:87-94.

Ibrahim, M.H., H.Z. Jaafar, E. Karimi, and A. Ghasemzadeh. 2012. Primary, secondary metabolites, photosynthetic capacity and antioxidant activity of the Malaysian herb kacip fatimah (Labisia Pumila Benth) exposed to potassium fertilization under greenhouse conditions. Intl. J. Mol. Sci. 13:15321-15342.

Kelly, J.T., M. Rossi, D.W. Johnson, and K.L. Campbell. 2017. Beyond sodium, phosphate and potassium: Potential dietary interventions in kidney disease. Semin. Dial. 30:197-202.

Kim, H.J., J.M. Fonseca, J.H. Choi, C. Kubota, and D.Y. Kwon. 2008. Salt in irrigation water affects the nutritional and visual properties of romaine lettuce (Lactuca sativa L.). J. Agr. Food Chem. 56:3772-3776.

Kong, X., Z. Luo, H. Dong, W. Li, and Y. Chen. 2017. Non-uniform salinity in the root zone alleviates salt damage by increasing sodium, water and nutrient transport genes expression in cotton. Sci. Rep. 7:2879.

Lattanzio, V., V.M.T. Lattanzio, and A. Cardinali. 2006. Role of phenolics in the resistance mechanism of plants against fungal pathogens and insects. Phytochem. Adv. Res. 23-26.

Li, H., T. Inokuchi, T. Nagaoka, M. Tamura, S. Hamada, and S. Suzuki. 2014. $\mathrm{NO}_{3}{ }^{-}$requirement and the quantitative management method of nutrient solution based on $\mathrm{NO}_{3}^{-}$supply in hydroponic culture of radish plants. J. Jpn. Soc. Hort. Sci. 83:44-51.
Liu, W., D. Zhu, D. Liu, X. Lu, and M. Geng. 2010. Comparative metabolic activity related to flavonoid synthesis in leaves and flowers of Chrysanthemum morifolium in response to $\mathrm{K}$ deficiency. Plant Soil 335:325-337.

Loka, D.A., D.M. Oosterhuis, D. Baxevanos, D. Vlachostergios, and W. Hu. 2018. How potassium deficiency alters flower bud retention on cotton (Gossypium hirsutum L.). Arch. Agron. Soil Sci. 65:521-536.

Lu, Z., J. Lu, Y. Pan, P. Lu, X. Li, R. Cong, and T. Ren. 2016a. Anatomical variation of mesophyl conductance under potassium deficiency has a vital role in determining leaf photosynthesis. Plant Cell Environ. 39:2428-2439.

Lu, Z., T. Ren, Y. Pan, X. Li, R. Cong, and J. Lu. 2016b. Differences on photosynthetic limitations between leaf margins and leaf centers under potassium deficiency for Brassica napus L. Sci. Rep. 6:21725.

Lu, Z., K. Xie, Y. Pan, T. Ren, J. Lu, M. Wang, Q. Shen, and S. Guo. 2019. Potassium mediates coordination of leaf photosynthesis and hydraulic conductance by modifications of leaf anatomy. Plant Cell Environ. 42:2231-2244.

Mahajan, S. and N. Tuteja. 2005. Cold, salinity and drought stresses: An overview. Arch. Biochem. Biophys. 444:139-158.

Mahmoudi, H., J. Huang, M.Y. Gruber, R. Kaddour, M. Lachaal, Z. Ouerghi, and A. Hannoufa. 2010. The impact of genotype and salinity on physiological function, secondary metabolite accumulation, and antioxidative responses in lettuce. J. Agr. Food Chem. 58:5122-5130.

Maillard, A., S. Diquelou, V. Billard, P. Laine, M Garnica, M. Prudent, J.M. Garcia-Mina, J.C. Yvin, and A. Ourry. 2015. Leaf mineral nutrient remobilization during leaf senescence and modulation by nutrient deficiency. Front. Plant Sci. 6:317.

Malejane, D.N., P. Tinyani, P. Soundy, Y. Sultanbawa, and D. Sivakumar. 2018. Deficit irrigation improves phenolic content and antioxidant activity in leafy lettuce varieties. Food Sci. Nutr. 6:334-341.

Menezes-Benavente, L., S.P. Kernodle, M. MargisPinheiro, and J.G. Scandalios. 2004. Saltinduced antioxidant metabolism defenses in maize (Zea mays L.) seedlings. Redox Rep. 9:29-36.

Mills, K.T., J. Chen, W. Yang, L.J. Appel, J.W. Kusek, A. Alper, P. Delafontaine, M.G. Keane, E. Mohler, A. Ojo, M. Rahman, A.C. Ricardo, E.Z. Soliman, S. Steigerwalt, R. Townsend, and J. He. 2016. Sodium excretion and the risk of cardiovascular disease in patients with chronic kidney disease. JAMA 315:2200-2210.

Minh, L.T., D.T. Khang, P.T. Thu-Ha, P.T. Tuyen, T.N. Minh, N.V. Quan, and T.D. Xuan. 2016. Effects of salinity stress on growth and phenolics of rice (Oryza sativa L.). Intl. Lett. Nat. Sci. 57:1-10.

Murthy, H.N., Y.S. Kim, S.Y. Park, and K.Y. Paek 2014. Biotechnological production of caffeic acid derivatives from cell and organ cultures of Echinacea species. Appl. Microbiol. Biotechnol. 98:7707-7717.

Nakano, Y., H. Sasaki, A. Nakano, K. Suzuki, and M. Takaichi. 2010. Growth and yield of tomato plants as influenced by nutrient application rates with quantitative control in closed rockwool cultivation. J. Jpn. Soc. Hort. Sci. 79:47-55.

Nguyen, D.T.P., N. Lu, N. Kagawa, and M. Takagaki. 2019. Optimization of photosynthetic photon flux density and root-zone temperature for enhancing secondary metabolite accumulation and production of coriander in plant factory. Agronomy 9:224.
Nowak, P.J., R. Wilk, A. Prymont-Przyminska, A. Zwolinska, A. Sarniak, A. Wlodarczyk, J. deGraft-Johnson, B. Mamelka, A. Zasowska-Novak, P. Bartnicki, S. Nowak, and M. Nowicki. 2017. Hemodialysis decreases the concentration of accumulated plant phenols in the plasma of patients on maintenance dialysis: Influence of residual renal function. Ther. Apher. Dial. 21:572-585.

Ogawa, A., T. Eguchi, and K. Toyofuku. 2012. Cultivation methods for leafy vegetables and tomatoes with low potassium content for dialysis patients. Environ. Control Biol. 50:407414.

Ogawa, A., S. Fujiya, and K. Toyofuku. 2014. A cultivation method for lettuce and spinach with high level of vitamin $\mathrm{C}$ using potassium restriction. Environ. Control Biol. 52:95-99.

Ouzounis, T., B. Razi-Parjikolaei, X. Frette, E. Rosenqvist, and C.O. Ottosen. 2015. Predawn and high intensity application of supplemental blue light decreases the quantum yield of PSII and enhances the amount of phenolic acids, flavonoids, and pigments in Lactuca sativa. Front. Plant Sci. 6:19.

Pettigrew, W.T. 2008. Potassium influences on yield and quality production for maize, wheat, soybean and cotton. Physiol. Plant. 133:670-681.

Renna, M., M. Castellino, B. Leoni, V.M. Paradiso, and P. Santamaria. 2018. Microgreens production with low potassium content for patients with impaired kidney function. Nutrients 10:675.

Schachtman, D. and W. Liu. 1999. Molecular pieces to the puzzle of the interaction between potassium and sodium uptake in plants. Trends Plant Sci. 4:281-287.

Shabala, S. and T.A. Cuin. 2007. Potassium transport and plant salt tolerance. Physiol. Plant. 133:651-669.

Shen, W.Q. 1988. Extraction of mixed solution for determination of chlorophyll content in rice leaf blade. Plant Physiol Commun. 3:62-64.

Silva, E.N., S.L. Ferreira-Silva, R.A. Viegas, and J.A.G. Silveira. 2010. The role of organic and inorganic solutes in the osmotic adjustment of drought-stressed Jatropha curcas plants. Environ. Exp. Bot. 69:279-285.

Singh, S.K. and V.R. Reddy. 2017. Potassium starvation limits soybean growth more than the photosynthetic processes across $\mathrm{CO}_{2}$ levels. Front. Plant Sci. 8:991.

Singleton, V.L., R. Orthofer, and R.M. LamuelaRaventos. 1999. Analysis of total phenols and other oxidation substrates and antioxidants by means of folin-ciocalteu reagent. Methods Enzymol. 299:152-178.

Spital, A. and R.H. Stems. 1988. Potassium homeostasis in dialysis patients. Semin. Dial. 1:14-20.

Sun, J., N. Lu, H. Xu, T. Maruo, and S. Guo. 2016. Root zone cooling and exogenous spermidine root-pretreatment promoting Lactuca sativa L. growth and photosynthesis in the hightemperature season. Front. Plant Sci. 7:368.

Talbott, L.D. and E. Zeiger. 1996. Central roles for potassium and sucrose in guard-cell osmoregulation. Plant Physiol. 111:1051-1057.

Tsukagoshi, S., E. Hamano, M. Hohjo, and F. Ikegami. 2016. Hydroponic production of lowpotassium tomato fruit for dialysis patients. Intl. J. Veg. Sci. 22:451-460.

Uribarri, J. 2018. An aspirational diet for dialysis patients: Evidence and theory. Semin. Dial. 31:236-243.

Vauzour, D., A. Rodriguez-Mateos, G. Gorona, M.J. Oruna-Concha, and J.P. Spencer. 2010. Polyphenols and human health: Prevention of 
disease and mechanisms of action. Nutrients 2:1106-1131.

Verhoeyen, M.E., A. Bovy, G. Collins, S. Muir, S. Robinson, C.H.R. de Vos, and S. Colliver. 2002. Increasing antioxidant levels in tomatoes through modification of the flavonoid biosynthetic pathway. J. Expt. Bot. 53:2099-2106.

Viacava, G.E., D.I. Roura, and M.V. Aguero. 2015. Antioxidant activity of butterhead lettuce: Evaluation of significant factors affecting antioxidant extraction and quantification. J. Food Meas. Charact. 9:206-214.

Wakeel, A., M. Farooq, M. Qadir, and S. Schubert. 2011. Potassium substitution by sodium in plants. Crit. Rev. Plant Sci. 30:401-413.

Wang, N., H. Hua, A.E. Eneji, Z. Li, L. Duan, and X. Tian. 2012a. Genotypic variations in photosynthetic and physiological adjustment to potassium deficiency in cotton (Gossypium hirsutum). J. Photochem. Photobiol. B 110:1-8.

Wang, X., C. Jiang, Y. Hao, D. Wang, Y. Xia, and F. Chen. 2012b. Review on the replacement of potassium by sodium or other ions. Soil Fert. Sci. Chin. 1:1-16.

Xu, H., M. Jokan, S. Tsukagoshi, and T. Maruo. The nutrient quantitative management based on low potassium supplied in hydroponic culture of lettuce. (In press.).

Yamori, W., E. Kondo, D. Sugiura, I. Terashima, Y. Suzuki, and A. Makino. 2016. Enhanced leaf photosynthesis as a target to increase grain yield: Insights from transgenic rice lines with variable Rieske FeS protein content in the cytochrome $b_{6} / f$ complex. Plant Cell Environ. 39:80-87.

Yamori, W., T. Nagai, and A. Makino. 2011. The rate-limiting step for $\mathrm{CO}_{2}$ assimilation at different temperatures is influenced by the leaf nitrogen content in several C(3) crop species. Plant Cell Environ. 34:764-777.

Yang, L., K.S. Wen, X. Ruan, Y. Zhao, F. Wei, and Q. Wang. 2018a. Response of plant secondary metabolites to environmental factors. Molecules 23:229.
Yang, X., S. Wei, B. Liu, D. Guo, B. Zheng, L. Feng, Y. Liu, F.A. Tomas-Barberan, L. Luo, and D. Huang. 2018b. A novel integrated non-targeted metabolomic analysis reveals significant metabolite variations between different lettuce (Lactuca sativa. L) varieties. Hort. Res. 5:33.

Yoshida, T., K. Sakuma, and H. Kumagai. 2016. Nutritional and taste characteristics of lowpotassium lettuce developed for patients with chronic kidney diseases. Hong Kong J. Nephrol. 16:42-45.

Zhang, G., M. Johkan, M. Hohjo, S. Tsukagoshi, and T. Maruo. 2017. Plant growth and photosynthesis response to low potassium conditions in three lettuce (Lactuca sativa) types. Hort. J. 86:229-237.

Zhishen, J., T. Mengcheng, and W. Jianming. 1999. The determination of flavonoid contents in mulberry and their scavenging effects on superoxide radicals. Food Chem. 64:555-559. 